\title{
Motives for visiting the national parks of Serbia
}

\author{
Živana Krejií́ \& Snežana Milićević
}

Keywords: visitor motives, sociodemographic characteristics, national parks, Serbia, sustainable development

\section{Abstract}

This paper explores motives for visiting national parks in Serbia. The results were obtained from the responses of 840 visitors who were surveyed while they were staying in Serbia's national parks during June 2020. The aim of the paper is to examine whether the motives for visiting the parks correlate with visitors' sociodemographic characteristics: gender, age, educational level and employment status. The results showed that there are statistically significant differences in motives to visit national parks in relation to gender, while among other sociodemographic characteristics such as employment status, education and age, the correlation is negligible. The scientific contribution of the paper lies in the possibility of applying the research results elsewhere, to help understand visitors' motives, as well as create attractive tourist offers in national parks based on sustainable development.

\section{Introduction}

National Parks (NP) and natural areas are powerful attractions for visitors, are major foreign currency earners, and constitute an important part of the tourist industry (Kruger \& Saayman 2009). Traditionally located in remote areas, NPs can present unique visitor attractions (Mayer et al. 2010; Amuquandoh 2017) and offer activities such as photography, observing plant and animal species and landscapes, sports and other recreational activities (hiking, biking, mountain climbing, rafting, fishing, etc.), and exploring cultural heritage. The approaches by individual countries differ from each other and their application in practice usually depends on the level of economic development of the country (Eagles 2009). Thus, NPs play crucial roles in the conservation of vulnerable natural ecosystems, but at the same time they may serve as tourist destinations and attract large numbers of people (Hibner et al. 2018).

There are five NPs in Serbia. Four of them are in mountainous areas: Šara Mountain NP, Fruška Gora NP, Kopaonik NP, Tara NP; the fifth is Đerdap Gorge NP. Đerdap NP is located in the north-eastern part of the Republic of Serbia and covers part of the Đerdap Gorge (Iron Gate) in the midstream of the river Danube (63786.48 ha). Fruška Gora NP is located in the north of Serbia in the Autonomous Province of Vojvodina (26672 ha), while Kopaonik NP is in the southern part of the country and covers the most valuable natural resources and highest parts of Kopaonik mountain (11969.04 ha). Tara NP is located in the far west of Serbia (24991.82 ha); the Šara Mountain NP is in the far south, in the Autonomous Province of Ko-

\footnotetext{
${ }^{1}$ Union University-Nikola Tesla, Faculty of Business Studies and Law, Belgrade, Serbia

2 University of Kragujevac, Faculty of Hotel Management and Tourism in Vrnjačka Banja, Vrnjačka Banja, Serbia.
}

sovo and Metohija (22805.43 ha) (Institute for Nature Conservation of Serbia 2020), see Figure 1.

The subject of this paper is the motives for visiting NPs in Serbia. A visitor survey was conducted during June 2020 in all five NPs. The aim of the paper is to examine whether motives for visiting NPs correlate with visitors' sociodemographic characteristics.

\section{Literature review}

The IUCN (2019) defines a NP as a large natural or near natural area that protects large-scale ecological processes, that has characteristic species and ecosystems, and which also has environmentally and culturally compatible spiritual, scientific, educational, recreational and visitor opportunities. NPs provide local communities with socio-economic benefits such as regulated and sustainable use of grazing, hunting and fishing, and other recreational and tourist opportunities (Al-Tokhais \& Thapa 2019). Important environmental factors attracting visitors to NPs are outdoor recreation opportunities, landscape and scenery, natural resources such as wildlife, and unspoilt nature (Haukeland et al. 2010). When people visit NPs, this impacts the various forms of economic activity of the local populations (Tomićević et al. 2011). Due to the growth in popularity of nature-based tourism, NPs have become increasingly attractive tourist destinations (Esfandiar et al. 2019). Nature-based tourism refers to all forms of tourism where natural environments form the primary attraction (Taczanowska et al. 2019; Coghlan \& Buckley 2012; Lundmark \& Muller 2010). In other words, fundamental to nature-based tourism are natural resources (e.g. mountains, lakes, rivers, forests and beaches) that are attractive enough to trigger travel (Lundberg \& Fredman 2012).

Activities that do not endanger the authenticity of nature are permitted in NPs, as are activities that relate to education, health, recreation and tourist needs, and the continuation of local traditional ways of life, in a 


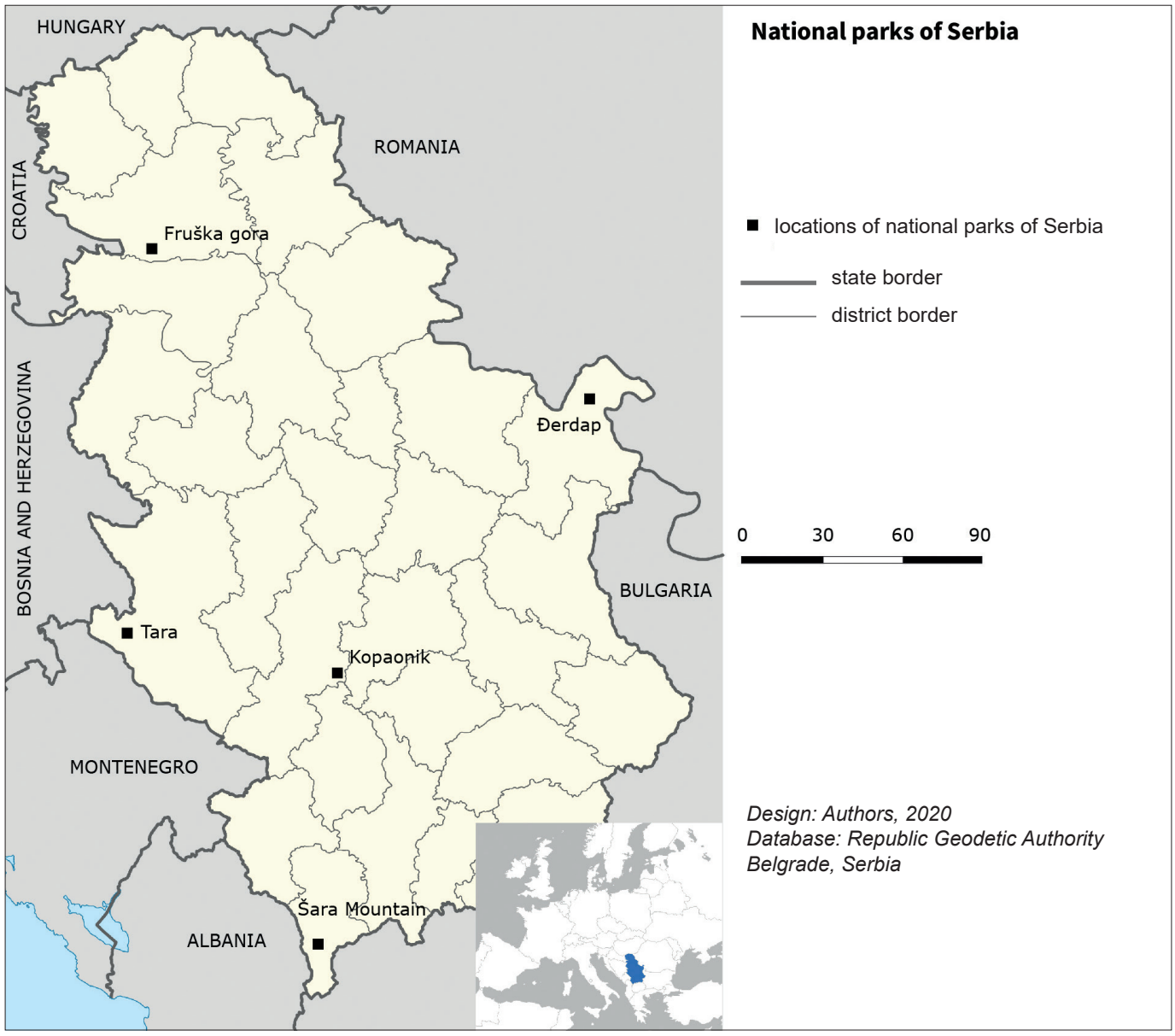

Figure 1 - National Parks in Serbia.

manner that does not endanger the survival of species, natural ecosystems and landscapes (Institute for $\mathrm{Na}$ ture Conservation of Serbia 2020). Azara et al. (2018) point out how deeply human health and wellbeing are connected to the benefits, both tangible (e.g. recreation) and intangible (e.g. sounds), which NPs provide for the visitor experience.

The reasons for visiting a certain NP can be as diverse as the visitors themselves. They include individual factors (e.g. personality, preferences, attitudes, way of life, sociodemographic characteristics), environmental or managerial factors (e.g. facilities, restrictions), and social factors (e.g. level of crowding, solitude, types of activities, accommodation) (Selvaag et al. 2020). Visitors to NPs are characterized by different motives, needs and expectations with regard to specific types of experience (Leask 2016). Insights into motives are central to developing tourism offers and the provision of satisfactory visitor experiences. Relaxation and the need to escape to a peaceful natural environment have been cited by nature-based tourists as one of the most important motives (Holden \& Sparrowhawk 2002). Kamri and Radam (2013) concluded that the primary motives for visiting Bako NP in Malaysia were to go on an excursion, social trip, nature tour or daytrip to escape the city. Basic motives for visiting NPs in Iran are to relax in nature, spend time with family and friends, seek adventure, escape routine and the urban environment, see wildlife, have a picnic, connect with nature, and improve quality of life in general (Reihanian et al.,2015). Gundersen et al. (2019) concluded that the main motive of visitors to Norwegian NPs during the summer season is hiking along marked tracks. Basic motives for visiting NPs in Zimbabwe are recreation and knowledge-seeking, appreciating wildlife and feeling close to nature $\mathrm{Mu}-$ tanga et al., 2017). Wildlife watching (primarily bisons, bears and olves), as well as organized hiking, orienteering, horse riding and mountain biking, are among the major motives to visit NPs in the US (Cherry 2018; Newsome \& Hughes 2018).

Numerous authors have analysed relationships between visitors' sociodemographic characteristics (such as gender, age, place of residence, educational level, employment status and income) and motivation (Kim et al. 2008; Chen et al. 2014; Newton et al. 2018; Milohnić et al. 2019; Moniz et al. 2020; Silva et al. 2020; Milićević et al. 2020). Motives such as relaxation, escape, nature or recreation have frequently emerged in different studies, although the most influential factor may vary according to the visitors' sociodemographic characteristics (Magadan-Díaz \& Rivas-García 2019). For example, Gundersen et al. (2015) state that hiking in Norwegian NPs attracts more visitors from higher 
socio-economic classes. Some authors state that gender differences in leisure behaviour may be related to the socio-cultural norms and values of people's home environment and social structure (Meng \& Uysal 2008). According to Ma et al. (2018), age has a positive influence on an individual's desire for relaxation and exploring nature in protected areas. Their study indicated that in southern China older Chinese visitors usually prefer exploring and appreciating nature in the region's protected areas. Further, they found that educational level is negatively correlated with how visitors feel they might be viewed by family and friends occupying higher social positions. The study by Tepavčević et al. (2019) on London residents found that younger people are less motivated to visit NPs in England than others - i. e. they are less motivated by enjoying the views, observation of plants and animals, visitor centres, and escape from the city. Visitors who left education after secondary school or college are more motivated by enjoyment of the scenery than are those with PhDs. Indeed, people with higher degrees are less motivated than any other group by enjoyment of the scenery. In terms of employment status, it has been found that there is a significant difference between the motives of visitors who are in employment and all others. The results of the study conducted at Kakum NP in Ghana show that eco-attractions and eco-based activities are becoming increasingly important motives for younger visitors. The results further revealed that search for adventure and acquisition of knowledge about the park and the environment are the main motives for female visitors (Adam et al. 2019). Saayman and Dieske (2015) state that females are more motivated than males to visit the Kgalagadi Transfrontier Park in South Africa for exploration. Further, only moderate statistically significant differences were found between the motivational factors and educational level of respondents. Respondents with a first or higher degree attribute less importance to park attributes and exploration than people with lower educational levels. Mutanga et al. (2017) investigated tourist motivation at two NPs in Zimbabwe (Gonarezhou and Matusadona). No significant differences in motivation were found between groups of different genders, educational level, income or nationality. Only age was found to correlate positively with two motives: recreation and knowledge-seeking, and appreciating wildlife. Cheung and Jim (2013) in their study of nature-based tourism in Hong Kong indicated that elderly visitors, as well as visitors with a university degree and higher income levels, tended to have higher expectations regarding the quality of nature-based tourism services and facilities.

\section{Research methodology}

The subject of our study is the motives of visitors to the NPs of Serbia in June 2020, with the aim of determining whether their motives correlated with their sociodemographic characteristics. Surveys were conducted in all the NPs in Serbia: Šara Mountain NP $(\mathrm{N}=159)$, Fruška Gora NP $(\mathrm{N}=174)$, Kopaonik NP $(\mathrm{N}=172)$, Tara NP $(\mathrm{N}=170)$, and Đerdap NP $(\mathrm{N}=165)$ (total 840). The surveys were conducted in one of two ways: the authors visited Šara Mountain and Đerdap Gorge and personally conducted a survey of visitors in the field; for the other three NPs, the questionnaire was forwarded to larger hotels located within the parks, whose guests completed it. The Omorika Hotel in Tara, the Grand Hotel in Kopaonik and the Fruške terme Hotel in Fruška Gora were chosen.

The questionnaire was identical for all the parks and had two parts. The first related to visitors' sociodemographic characteristics: gender, age, educational level and employment status. The second part consisted of 13 closed questions, covering the basic motives for visiting NPs. Respondents rated the motives using a 5 -point Likert scale $(1=$ completely disagree, $5=$ completely agree). The motives were chosen by consulting earlier studies (Hibner et al. 2018; Amuquandoh 2017; Gundersen et al. 2015; Kamri \& Radam 2013).

Based on the research objective, the following hypotheses were formulated:

$\mathrm{H}_{1}$ : There are statistically significant differences in motives for visiting NPs in relation to visitors' age;

$\mathrm{H}_{2}$ : There are statistically significant differences in motives for visiting NPs in relation to visitors' educational level;

$\mathrm{H}_{3}$ : There are statistically significant differences in motives for visiting NPs in relation to visitors' employment status;

$\mathrm{H}_{4}$ : There are statistically significant differences in motives for visiting NPs in relation to visitors' gender.

Non-parametric techniques that are suitable for ordinal sizes were used in the data processing and analysis process: Spearman's rank correlation coefficient (Spearman's ) and the Kruskal-Wallis test were used with the aim of measuring correlations, and determining the strength and direction of the linear relationship between the variables - that is, between motives for visiting NPs and selected sociodemographic characteristics of the visitors.

\section{Results and discussion}

The survey included 840 visitors, of whom $50 \%$ were women and $50 \%$ were men. The largest age group was the 31-40-year-olds (41.3\%). The majority had a Bachelor's degree (54.6\%); 62.7\% were employed and $37.3 \%$ were unemployed (Table 1$)$.

The correlation describes the strength and direction of a linear relationship between two variables. Spearman's rank correlation coefficient $r_{0}$ was calculated using SPSS Statistics v21.This coefficient is appropriate for ordinal or rankable sizes. The correlation value can be between 0 and 1. Pallant (2013) provides the following guidelines for correlation magnitude: 
Table 1 - Visitors' sociodemographic characteristics.

\begin{tabular}{|l|l|r|r|}
\cline { 3 - 4 } \multicolumn{2}{c|}{} & Frequency & $(\%)$ \\
\hline \multirow{4}{*}{ Gender } & Male & 420 & 50.0 \\
\cline { 2 - 4 } & Female & 420 & 50.0 \\
\cline { 2 - 4 } & 220 & 22 & 2.6 \\
\cline { 2 - 4 } & $21-30$ & 227 & 27.0 \\
\cline { 2 - 4 } & $31-40$ & 347 & 41.3 \\
\cline { 2 - 4 } & $41-50$ & 109 & 13.0 \\
\cline { 2 - 4 } & $51-60$ & 64 & 7.6 \\
\cline { 2 - 4 } & $61-70$ & 71 & 8.5 \\
\hline Education & High school graduate & 142 & 16.9 \\
\cline { 2 - 4 } & Bachelor's degree & 459 & 54.6 \\
\cline { 2 - 4 } & Master's degree & 201 & 23.9 \\
\cline { 2 - 4 } & Doctorate & 38 & 4.6 \\
\hline & Employed & 527 & 62.7 \\
\cline { 2 - 4 } & Unemployed & 313 & 37.3 \\
\hline
\end{tabular}

low correlation for $0.10<\mathrm{r}_{0}<0.29$; mean correlation for $0.30<\mathrm{r}_{0}<0.49$ high correlation for $0.50<\mathrm{r}_{0}<1$. These guidelines apply whether or not there is a negative sign in front of the coefficient $r_{0}$. A negative sign indicates its direction, not its strength.

Table 2 presents the results of the Spearman correlation, showing the relationship between visitors' age $\left(y_{1}\right)$ and their level of education $\left(y_{2}\right)$ on the one hand, and their motives for visiting NPs on the other. Motives are grouped into the following categories $\left(a_{1}-a_{13}\right)$ :

$\left(a_{1}\right)$ New experiences and meeting people with similar interests;

$\left(\mathrm{a}_{2}\right)$ Active boliday (biking, biking, mountain climbing, etc.);

(a) Outdoor activities for the whole family (sport, recreation, adventure parks, etc.);

$\left(\mathrm{a}_{4}\right)$ Getting to know the local way of life (culture, traditions, gastronomy, etc.);

(a $a_{5}$ Camping \& picnicking;

(a) Wildlife watching, birdwatching \& butterfly watching;

(a) Enjoying viewpoints and landscapes;

$\left(a_{8}\right)$ Study and observation of protected plant species;

$\left(\mathrm{a}_{9}\right)$ Foraging for medicinal herbs, forest fruits or mushrooms;

$\left(a_{10}\right)$ Environmental events and workshops;

$\left(a_{11}\right)$ Educational eco-tours of the specific features of NPs, accompanied by expert guides;

$\left(\mathrm{a}_{12}\right)$ Cultural and historical heritage;

$\left(a_{13}\right)$ Passive holiday in preserved nature.

The correlation between age of visitors $\left(y_{1}\right)$ and most of the variables observed is weak. More precisely, there is only a slight influence (i. e. correlation) between visitor age on the one hand, and the variables $\left(a_{1}\right)-\left(a_{5}\right)$ (statistically significant level: $\left.p>0.05\right)$. The results of the bivariate correlation test show the same for $\left(\mathrm{a}_{8}\right),\left(\mathrm{a}_{11}\right)$ and $\left(\mathrm{a}_{12}\right)$. A weak correlation, $p<0.05$, exists with respect to variables $\left(a_{6}\right),\left(a_{7}\right),\left(a_{9}\right),\left(a_{10}\right)$ and $\left(a_{13}\right)$. The only exception is $\left(a_{7}\right)$, which shows that the most significant motive for older people (aged 61 to 70) to visit NPs is Enjoying viewpoints and landscapes. The relationship between visitors' educational level $\left(\mathrm{y}_{2}\right)$ and all observed variables $\left(a_{1}\right)-\left(a_{13}\right)$ is also weak, and there are no statistically significant differences except for the variable $\left(\mathrm{a}_{13}\right)$, Passive holiday in preserved nature, $(p<0.05)$. The value of the Spearman coefficient is only slightly more pronounced - i.e. $r_{0}>0.10$. There is little correlation between visitors' level of education and variables $\left(a_{5}\right)$ and $\left(a_{7}\right)$. The level of significance for educational level in relation to variable $\left(a_{11}\right)$ is less than 0.05 , indicating that educational eco-tours of the specific nature of the NPs, accompanied by expert guides is the most important motive for those with a Master's or doctorate to visit the NPs. The negative sign in front of the coefficient value $\left(a_{13}\right)$ explains that these visitors had higher expectations of educational trips generally.

For the purpose of clarifying the statistical back layer, for each field the strongest correlation in $\left(\mathrm{y}_{1}\right)-$ $\left(a_{13}\right)$ was identified, i.e. the correlation between visitor age and the variable $\left(\mathrm{a}_{13}\right)$ Passive holiday in preserved nature. The values of the Spearman's correlation coefficients are shown in Table 3 ; in this case, $\mathrm{r}_{0}=-0.249$. The negative sign indicates that there is a correlation between visitor age and the variable $\left(\mathrm{a}_{2}\right)$ Active holiday (biking, biking, mountain climbing, etc.), and that this is the most significant motive for visitors up to 30 years of age. However, of the total number of respondents, age is correlated with the variable $\left(a_{13}\right)$ in only $6 \%$ of cases. This percentage is obtained by squaring the Spearman's coefficient.

It is concluded that there are no statistically significant differences in motives for visiting NPs in relation to age. In this study, results show that visitors aged over 61 are not motivated by active holidays, while visitors aged 30 to 60 have little interest in passive holidays. Therefore, hypothesis $\mathrm{H}_{1}$ is rejected. Further, hypothesis $\mathrm{H}_{2}$ is rejected because the results of the research show that there are no statistically significant differences and that the correlations between visitors' educational level and all 13 variables (i. e. motives for visiting NPs) are very weak.

Hypothesis $\mathrm{H}_{3}$ requires examining whether there are statistically significant differences in motives for visiting NPs in relation to employment status. The

Table 2 - Results of Spearman's Correlations for visitors' motives by Correlation Coefficient and Sig. (2-tailed): visitors' age $\left(y_{1}\right)$ and educational level $\left(y_{2}\right)$

\begin{tabular}{|c|c|c|c|c|c|c|c|c|c|c|c|c|c|}
\hline$r_{0}(p)$ & $a_{1}$ & $a_{2}$ & $a_{3}$ & $a_{4}$ & $a_{5}$ & $a_{6}$ & $a_{7}$ & $a_{8}$ & $a_{9}$ & $a_{10}$ & $a_{11}$ & $a_{12}$ & $a_{13}$ \\
\hline$y_{1}$ & $\begin{array}{r}-.050 \\
(.472)\end{array}$ & $\begin{array}{r}-.029 \\
(.680)\end{array}$ & $\begin{array}{r}-.038 \\
(.589)\end{array}$ & $\begin{array}{r}-.011 \\
(.870)\end{array}$ & $\begin{array}{r}.042 \\
(.546)\end{array}$ & $\begin{array}{r}-.220 \\
(.001)\end{array}$ & & & & & & & \\
\hline$y_{2}$ & $\begin{array}{r}.013 \\
(.850)\end{array}$ & $\begin{array}{r}.130 \\
(.059)\end{array}$ & $\begin{array}{r}.039 \\
(.574)\end{array}$ & $\begin{array}{r}.053 \\
(.448)\end{array}$ & $\begin{array}{r}.115 \\
(.098)\end{array}$ & $\begin{array}{r}.094 \\
(.176)\end{array}$ & $\begin{array}{r}.115 \\
(.097)\end{array}$ & $\begin{array}{r}.130 \\
(.060)\end{array}$ & $\begin{array}{r}.017 \\
(.806)\end{array}$ & $\begin{array}{r}.027 \\
(.699)\end{array}$ & $\begin{array}{r}-.144 \\
(.037)\end{array}$ & $\begin{array}{c}-.071 \\
(.305)\end{array}$ & $\begin{array}{r}.010 \\
(.881)\end{array}$ \\
\hline
\end{tabular}


Table 3 - Spearman's Correlation (zero-order correlation) between (y1) and (a13). ${ }^{* *}$ Correlation is significant at the 0.01 level (2-tailed).

\begin{tabular}{|l|l|l|r|r|}
\cline { 3 - 5 } \multicolumn{2}{l|}{} & & $\mathbf{y}_{1}$ & $\mathbf{a}_{13}$ \\
\hline $\begin{array}{l}\text { Spearman's } \\
\text { Correlation }\end{array}$ & $y_{1}$ & Correlation Coefficient & 1.000 & $-.249^{*}$ \\
\cline { 3 - 5 } & & Sig. (2-tailed) & & .000 \\
\cline { 2 - 5 } & $\mathrm{a}_{13}$ & Correlation Coefficient & $-.249^{* *}$ & 1.000 \\
\cline { 3 - 5 } & & Sig. (2-tailed) & .000 & \\
\hline
\end{tabular}

Table 4 - Motives for visiting national parks in relation to employment status.

\begin{tabular}{|l|r|r|r|r|r|r|r|}
\hline Motives & $\mathbf{a}_{1}$ & $\mathbf{a}_{2}$ & $\mathbf{a}_{3}$ & $\mathbf{a}_{4}$ & $\mathbf{a}_{5}$ & $\mathbf{a}_{6}$ & $\mathbf{a}_{7}$ \\
\hline Chi-Square & 7.099 & .410 & .349 & .031 & 1.426 & .421 & 4.793 \\
\hline df & 1 & 1 & 1 & 1 & 1 & 1 & 1 \\
\hline Asymp. Sig. & .008 & .522 & .555 & .860 & .232 & .516 & .029 \\
\hline Motives & $\mathbf{a}_{8}$ & $\mathbf{a}_{9}$ & $\mathbf{a}_{10}$ & $\mathbf{a}_{11}$ & $\mathbf{a}_{12}$ & $\mathbf{a}_{13}$ \\
\hline Chi-Square & .003 & .030 & 4.143 & 13.128 & .053 & 3.258 \\
\hline df & 1 & 1 & 1 & 1 & 1 & 1 \\
\hline Asymp. Sig. & .955 & .862 & .042 & .000 & .819 & .071 \\
\hline
\end{tabular}

most important motives of visitors who are in work are: $\left(\mathrm{a}_{4}\right)$ Getting to know the local way of life (culture, traditions, gastronomy, etc.); ( $\left.\mathrm{a}_{5}\right)$ Camping \& picnicking; $\left(\mathrm{a}_{9}\right)$ Foraging for medicinal herbs, forest fruits or mushrooms. Unemployed visitors stated the following motives: $\left(a_{1}\right)$ New experiences and meeting people of similar interests; $\left(\mathrm{a}_{2}\right)$ Active boliday (biking, biking, mountain climbing, etc.); ( $\mathrm{a}_{3}$ ) Outdoor activities for the whole family (sport, recreation, adventure parks, etc.).

The Kruskal-Wallis test of all variables from $\left(a_{1}\right)$ to $\left(a_{13}\right)$ in relation to employment status showed significance levels greater than 0.005 for all. It also showed that there were no statistically significant differences among motives for visiting NPs in relation to visitors' employment status. Therefore, hypothesis $\mathrm{H}_{3}$ is rejected.

This study finds that visitors' age, educational level and employment status and their motives for visiting the NPs are negatively correlated. These results overlap with the results of some earlier studies. For instance, Mutanga et al. (2017), who conducted research in two NPs in Zimbabwe, found no significant differences in tourists' motives for visiting NPs in relation to educational level; they did, however, find that age correlated positively with some motives (recreation and knowledge-seeking, and appreciating wildlife). The findings of other researchers also indicate a correlation between age and motives for visiting protected areas: Ma et al. (2018) showed that older visitors are more motivated to visit protected areas, while Tepavčević et al. (2019) found that younger visitors are less motivated than others to visit NPs.

Hypothesis $\mathrm{H}_{4}$ tests whether there are statistically significant differences in motives for visiting NPs relative to gender (Table 5). The results show that the most important motives for male visitors are: $\left(a_{1}\right)$ New experiences and meeting people of similar interests;
Table 5 - Motives for visiting national parks in relation to gender (1-men; 2-women). $N$ total $=840 ; N$ men $=420$; $N$ women $=420$

\begin{tabular}{|c|c|c|}
\hline Motives & Gender & Mean Rank \\
\hline \multirow{2}{*}{$a_{1}$} & 1 & 420.73 \\
\hline & 2 & 415.08 \\
\hline \multirow[t]{2}{*}{$a_{2}$} & 1 & 417.58 \\
\hline & 2 & 403.94 \\
\hline \multirow[t]{2}{*}{$a_{3}$} & 1 & 415.60 \\
\hline & 2 & 319.93 \\
\hline \multirow[t]{2}{*}{$a_{4}$} & 1 & 428.74 \\
\hline & 2 & 423.07 \\
\hline \multirow[t]{2}{*}{$a_{5}$} & 1 & 402.76 \\
\hline & 2 & 418.55 \\
\hline \multirow[t]{2}{*}{$a_{6}$} & 1 & 420.01 \\
\hline & 2 & 418.12 \\
\hline \multirow[t]{2}{*}{$a_{7}$} & 1 & 419.48 \\
\hline & 2 & 409.77 \\
\hline \multirow[t]{2}{*}{$a_{8}$} & 1 & 420.02 \\
\hline & 2 & 420.33 \\
\hline \multirow[t]{2}{*}{$a_{9}$} & 1 & 414.77 \\
\hline & 2 & 416.05 \\
\hline \multirow[t]{2}{*}{$a_{10}$} & 1 & 414.38 \\
\hline & 2 & 408.84 \\
\hline \multirow[t]{2}{*}{$a_{11}$} & 1 & 419.98 \\
\hline & 2 & 406.14 \\
\hline \multirow[t]{2}{*}{$a_{12}$} & 1 & 416.52 \\
\hline & 2 & 414.73 \\
\hline \multirow[t]{2}{*}{$a_{13}$} & 1 & 413.28 \\
\hline & 2 & 399.67 \\
\hline
\end{tabular}

$\left(\mathrm{a}_{2}\right)$ Active boliday (biking, biking, mountain climbing, etc.); $\left(\mathrm{a}_{3}\right)$ Outdoor activities for the whole family (sport, recreation, adventure parks, etc.); ( $\left.\mathrm{a}_{4}\right)$ Getting to know the local way of life (culture, traditions, gastronomy, etc.); $\left(\mathrm{a}_{10}\right)$ Environmental events and workshops; $\left(\mathrm{a}_{12}\right)$ Cultural-historical heritage, and $\left(\mathrm{a}_{13}\right)$ Passive holiday in preserved nature. On the other hand, female visitors gave the following motives: $\left(\mathrm{a}_{5}\right)$ Camping \& picnicking and $\left(\mathrm{a}_{9}\right)$ Foraging for medicinal herbs, forest fruits or mushrooms. The Kruskal-Wallis test shows that there are statistically significant differences in motives for visiting NPs in relation to gender. Therefore, hypothesis $\mathrm{H}_{4}$ is accepted. This finding is consistent with earlier observations made by Adam et al. (2019) and by Saayman and Dieske (2015), who also pointed out statistically significant differences in motives for visiting NPs in Africa in relation to their gender - namely that females are more motivated than males to visit the NPs. However, these results contrast with those of Mutanga et al. (2017), who found no statistically significant differences in motives for visiting NPs in Zimbabwe in relation to gender.

The focus of this study is not on the NPs of Serbia individually. However, it is worth noting that there are differences in visitors' motives, conditioned by numerous factors specific to individual NPs - primarily altitude, terrain configuration, richness of flora and fauna, cultural and historical heritage, quality of infrastructure and tourism superstructure. The main motives for visiting Šara Mountain NP are Active boliday 
(biking, biking, mountain climbing, etc.) and Wildlife watching, birdwatching \& butterfly watching, whereas for Fruška Gora NP they are Enjoying viewpoints and landscapes and Getting to know the local way of life (culture, traditions, gastronomy, etc.). Visitors to Kopaonik NP are motivated by Active holiday (biking, biking, mountain climbing, etc.), New experiences and meeting people of similar interests and Foraging for medicinal herbs, forest fruits or mushrooms. Tara NP is most visited for Outdoor activities for the whole family (sport, recreation, adventure parks), Wildlife watching, birdwatching \& butterfly watching and Camping \& picnicking, while Đerdap NP attracts those motivated by Passive boliday in preserved nature and Environmental events and workshops.

\section{Conclusion}

NPs are protected areas of exceptional natural and cultural value, for which individuals, in addition to the state, should feel responsible. A preserved environment, diverse landscapes, endemic species, and a range of activities that can be practised there make NPs very attractive for visits.

In this study, conducted in the NPs of Serbia, the correlations between visitors' motives and their sociodemographic characteristics were examined. The most significant sociodemographic characteristics (gender, age, educational level and employment status) were identified using Spearman's Correlation and the Kruskal-Wallis test. Visitors aged over 61 identify the main motive for their visit to NPs as Enjoying viewpoints and landscape. However, there is no statistically significant correlation between visitor age and the other variables examined $\left(\mathrm{H}_{1}\right)$. There is also no statistically significant correlation between educational level and motives for visiting NPs in Serbia $\left(\mathrm{H}_{2}\right)$, or between employment status and motives $\left(\mathrm{H}_{3}\right)$. In contrast, there is a statistically significant correlation between motives for visiting NPs and gender, i. e. there are differences in the way men and women spend their time in NPs. Therefore, hypothesis H4 is confirmed.

The results of the research have scientific and practical values. There being no similar research on this topic in Serbia, the study makes a contribution to scientific research by integrating results from all NPs in Serbia concerning the motivation for visiting the parks. The practical contribution lies in the possibility of the results being used by others: managers of other NPs, tourism service providers, travel agencies, guides, public institutions that implement tourism development plans, as well as creators of tourism development strategies in protected areas.

On the other hand, the main limitations of the research relate to the period in which the survey was conducted. Future research on the motivations to visit Serbia's NPs should be conducted throughout the year, in order to gain a better insight into factors that depend on the season (i. e. tourist season / off-season; summer/winter), and activities that can be practised, which may be the main motive of the visit. Further, the questionnaire can be expanded to cover satisfaction with the tourist offers available, and respect for the principles of sustainable development and environmental protection.

\section{References}

Adam, I., C.A. Adongo \& F.E. Amuquandoh 2019. A structural decompositional analysis of eco-visitors' motivations, satisfaction and post-purchase behavior. Journal of Ecotourism 18(1): 60-81.

AL-Tokhais, A. \& B. Thapa 2019. Stakeholder Perspectives Towards National Parks and Protected Areas in Saudi Arabia. Sustainability 11(8): 2323.

Amuquandoh, F.E. 2017. Tourists' motivations for visiting Kakum National Park, Ghana. Ghana Journal of Geography 9(1): 152-168.

Azara, I., E. Michopoulou, F. Niccolini, B.D. Taff \& A. Clarke 2018. Tourism, Health, Wellbeing and Protected Areas CABI.

Chen, G., J. Bao \& S.S. Huang 2014. Segmenting Chinese Backpackers by Travel Motivations. International Journal of Tourism Research 16(4): 355-367.

Cherry, C., K.M. Leong, R. Wallen \& D. Buttke 2018. Risk-enhancing behaviors associated with human injuries from bison encounters at Yellowstone National Park, 2000-2015. One Health 6: 1-6.

Cheung, L.T.O. \& C.Y. Jim 2013. Ecotourism service preference and management in Hong Kong. International Journal of Sustainable Development \& World Ecology 20(2): 182-194.

Coghlan, A. \& R.C. Buckley 2012. Nature-Based Tourism. In: Holden A. \& D. Fennell (eds), A Handbook of Tourism and the Environment. 334-344.London.

Eagles, P.F.J. 2009. Governance of recreation and tourism partnerships in parks and protected areas. Journal of Sustainable Tourism 17(2): 231-248.

Esfandiar, K., M. Sharifi-Tehrani, S. Pratt \& L. Altinay 2019. Understanding entrepreneurial intentions: A developed integrated structural model approach. Journal of Business Research 94: 172-182.

Gundersen, V., M. Mehmetoglu, O.I. Vistad \& O. Andersen 2015. Linking visitor motivation with attitude towards management restrictions on use in a National Park. Journal of Outdoor Recreation and Tourism 9: 77-86.

Gundersen, V., O.I. Vistad, M. Panzacchi, O. Strand \& B. van Moorter 2019. Large-scale segregation of tourists and wild reindeer in three Norwegian National Parks: Management implications. Tourism Management 75: 22-33.

Haukeland, J.V., B. Grue \& K. Veisten 2010. Turning National Parks into Tourist Attractions: Nature orientation and Quest for Facilities. Scandinavian Journal of Hospitality and Tourism 10(3): 248v271.

Hibner, J., K. Taczanowska, A. Zieba, C. Brandeburg, A. Muhar \& J. Balon 2018. Visitor profiling for cable car mountain destinations as a basis for pro- 
tected area management: a case study of the summer season in the Tatra Mountains at Kasprowy Wierch (Poland) and Skalnaté Pleso (Slovakia). eco.mont - Journal on protected mountain areas research and management 10(1): 24-35.

Holden, A. \& J. Sparrowhawk 2002. Understanding the motivations of ecotourists: the case of trekkers in Annapurna, Nepal. International Journal of Tourism Research 4(6): 435-446.

Institute for Nature Conservation of Serbia, 2020. Available at: http://www.zzps.rs/wp/nacionalniparkovi/?lang $=$ en $($ accessed 28.5 .2020$)$.

IUCN 2019. Category II: National Park. Available at: https://www.iucn.org/theme/protectedareas/ about/protected-areas-categories/category-ii-national-park (accessed 30/06/2020).

Kamri, T. \& A. Radam 2013. Visitors' Visiting Motivation: Bako National Park, Sarawak. Procedia-Social and Behavioral Sciences 101: 495-505.

Kim, S.S., M. Kim, J. Park \& Y. Guo 2008. Cave tourism: 'Tourists' Characteristics, Motivations to Visit, and the Segmentation of Their Behavior. Asia Pacific Journal of Tourism Research 13(3): 299-318.

Kruger, M. \& M. Saayman 2010. Travel motivation of tourists to Kruger and Tsitsikamma National Parks: A comparative study. African Journal of Wildlife Research 40(1): 93-102.

Leask, A. 2016. Visitor attraction management: A critical review of research 2009-2014. Tourism Management 57: 334-361.

Lundberg, C. \& P. Fredman 2012. Success factors and constraints among nature-based tourism entrepreneurs. Current Issues in Tourism 15(7): 649-671.

Lundmark, L. \& D.K. Müller 2010. The supply of nature-based tourism activities in Sweden. Tourism: $A n$ International Interdisciplinary Journal 58(4): 379-393.

Ma, A.T.H., A.S.Y Chow, L.T.O Cheung, K.M.Y. \& S. Liu 2018. Impacts of Tourists' Sociodemographic Characteristics on the Travel Motivation and Satisfaction: The Case of Protected Areas in South China. Sustainability 10(10): 3388.

Magadan-Diaz, M. \& J. Rivas-Garcia 2019. Sustainable tourism in mountain protected areas of Asturias: an analysis from tourists' perceptions and profiles. Sustainable Development of Mountain Territories 4(42): 459-474.

Mayer M., M. Müller, M. Woltering, J. Arnegger, J. $\&$ H. Job 2010. The economic impact of tourism in six German National Parks. Landscape and Urban Planning 97(2): 73-82.

Meng, F. \& M. Uysal 2008. Effects of Gender Differences on Perceptions of Destination Attributes, Motivations, and Travel Values: An Examination of a Nature-Based Resort Destination. Journal of Sustainable Tourism 16(4): 445-466.

Milićević, S., N. Đorđević \& Ž. Krejić 2020. Research on tourists' attitudes on the potential of Goč mountain for the development of eco-tourism. Economics of Agriculture 67(1): 223-238.
Milohnić, I., I. Licul \& I. Predović 2019. The Importance of Understanding the Connection Between the Characteristics and Motivation of Visitors: Empirical Analysis of a Croatian Tourist Event. Journal of the Polytechnic of Rijeka 7(1): 109-125.

Moniz, A.I., T. Medeiros, O. Silva \& J. Ferreira 2020. The Effects of Senior Tourists' Characteristics on Travel Motivation. In: Rocha, Á., A. Abreu, J. Vidal de Carvalho, D. Liberato, E. Alén González, P. Liberato, Advances in Tourism, Technology and Smart Systems: 415-425. Singapore.

Mutanga, C.N., S. Vengesayi, O. Chikuta, N. Muboko \& E. Gandiwa 2017. Travel motivation and tourist satisfaction with wildlife tourism experiences in Gonarezhou and Matusadona National Parks, Zimbabwe. Journal of Outdoor Recreation and Tourism 20: 1-18.

Newsome, D. \& M. Hughes 2018. The contemporary conservation reserve visitor phenomenon. Biodiversity and Conservation 27(2): 521-529.

Newton, J.N., P. Newman, B.D. Taff, Y.H. Shr, C. Monz \& A. D'Antonio 2018. If I can find a parking spot: A stated choice approach to Grand Teton National Park visitors' transportation preferences. Journal of Outdoor Recreation and Tourism. doi: 10.1016/j. jort.2018.04.001

Pallant, J. 2013. SPSS survival manual. McGraw-Hill Education (UK).

Reihanian, A., T.W. Hin, E. Kahrom, E., N.Z. Binti Mahmood \& A. Bagherpour Porshokouh 2015. An examination of the effects of push and pull factors on Iranian National Parks: Boujagh National Park Iran. Caspian Journal of Environmental Sciences 13(3): 197-206.

Saayman, M. \& T. Dieske 2015. Segmentation by motivation of tourists to the Kgalagadi Transfrontier Park. South African Journal of Business Management 46(2): 77-87.

Selvaag, S.K, Ø. Aas \& V. Gundersen 2020. Linking visitors' spatial preferences to sustainable visitor management in a Norwegian National Park. eco.mont Journal on protected mountain areas research and management 12(1): 27-33.

Silva, O., T. Medeiros, A.I. Moniz, L.Tomas, S. Furtado \& J. Ferreira 2020. Tourists' characteristics, travel motivation and satisfaction. In: Rocha, Á., A. Abreu, J. Vidal de Carvalho, D. Liberato, E. Alén González, P. Liberato, Advances in Tourism, Technology and Smart Systems 171: 427-436. Singapore.

Taczanowska, K., L.M. González, X. García-Massó, A.Zięba, C. Brandenburg, A. Muhar \& J. Toca-Herrera 2019. Nature-based Tourism or Mass Tourism in Nature? Segmentation of Mountain Protected Area Visitors Using Self-organizing Maps (SOM). Sustainability 11(5): 1314.

Tepavčević, J., U. Miljanić, M. Bradnić \& S. Janićević 2019. Impact of London residents' sociodemographic characteristics on the motives for visiting National Parks. Journal of the Geographical Institute "Jovan Cvijic" SASA 69(2): 135-146. 
Tomićević, J., I. Bjedov, D. Obratov-Petković \& M. Milovanović 2011. Exploring the Park- People Relation: Collection of Vaccinium Myrtillus L. by Local People from Kopaonik National Park in Serbia. Environmental Management 48(4): 835-846.

Vespestad, M.K. \& F. Lindberg 2011. Understanding nature-based tourist experiences: An ontological analysis. Current Issues in Tourism 14(6): 563-580.

\section{Authors}

Živana Krejić

is an Assistant Professor, at Union University-Nikola Tesla, Faculty of Business Studies and Law,
Jurija Gagarina 149a, 11070 Belgrade, Serbia. email: zkrejic@yahoo.com; ORCID ID https://orcid. org/0000-0003-2490-5755

\section{Snežana Milićević}

is an Associate Professor, at the University of Kragujevac, Faculty of Hotel Management and Tourism in Vrnjačka Banja, Vojvođanska 5a, Vrnjačka Banja, Serbia. email: snezana.milicevic@kg.ac.rs; ORCID ID https://orcid.org/0000-0002-1972-9585 